\title{
The Impact of the Number of a Trustee's Social Identities on Their Trustworthiness
}

\author{
Ziqiang Xin and Yue Zhang \\ Department of Psychology at School of Sociology and Psychology, Central University of Finance and Economics, Beijing, China
}

\begin{abstract}
A Ithough many studies have focused on how trustees' particular or single social identity affects their trustworthiness, only one study has revealed that trustees with multiple social identities are judged as more trustworthy than those with a single identity. However, the study could not show how trustworthiness systematically changes with an increasing number of social identities. The present study addressed this issue and further explored in two experiments whether the growth trend of trustworthiness was particular to social identities. Experiment 1 showed that when the number of trustees' social identities increased, they were judged as more trustworthy. Experiment 2 found that trustees with more social identities were judged as more trustworthy, whereas the amount of trustees' personal physical information did not have that large effect in facilitating trustworthiness. These results demonstrate the special influence of social identity information on trust or trustworthiness.
\end{abstract}

Keywords: social identity, social identity complexity, trustworthiness, interpersonal trust

In some social occasions, for the sake of getting acquainted with each other quickly, we may need to exchange personal or business cards. Most people choose to present social identities on their cards, because this information is beneficial to improving trustworthiness (Brewer, 2008; Güth, Levati, \& Ploner, 2008; Kramer, 1999; Lount, 2010; Maddux \& Brewer, 2005). However, some people present several social identities, while others present only one social identity. Does the number of social identities influence trustworthiness? We know little about this question. Most previous studies have focused on the impact of a particular or single social identity (such as nationality or occupation) on trustworthiness by distinguishing in-group from out-group members (e.g., Brewer \& Brown, 1998; Yuki, Maddux, Brewer, \& Takemura, 2005). The present research aimed to investigate how trustees' trustworthiness changes with the quantity of their social identities, which reflects the complexity of social identity.

\section{Social Identity Complexity and Trustworthiness}

In real life, individuals might simultaneously possess multiple social identities (Ashforth, Harrison, \& Corley, 2008; Blader, 2007) or think of themselves as members of several different social groups (Chiu \& Cheng, 2007;
Roccas \& Brewer, 2002). The structure of multiple social identities can be measured in terms of social identity complexity, a concept proposed by Roccas and Brewer in 2002, which refers to the way in which individuals subjectively represent the relationships among their multiple in-group memberships. Individuals with low social identity complexity see their in-groups as highly overlapping and convergent, whereas those with high social identity complexity see their different in-groups as distinct entities. For instance, a female lawyer with low social identity complexity may consider only other female lawyers as in-group members and regard men or women who are not lawyers as out-group members; yet, a female lawyer with high social identity complexity might regard a male lawyer as an out-group member on the gender dimension but as an ingroup member on the occupation dimension. Empirical studies bringing insights from social identity complexity theory have mostly focused on intergroup perception and attitude, finding that higher social identity complexity was associated with greater out-group tolerance (Roccas \& Brewer, 2002), more positive attitudes toward specific outgroups (Miller, Brewer, \& Arbuckle, 2009), less in-group favouritism (Schmid, Hewstone, \& Al Ramiah, 2013), and lower intergroup bias (Crisp, Turner, \& Hewstone, 2010). Concerning the relationship of social identity complexity

Address for correspondence: Prof. Ziqiang Xin, Department of Psychology at School of Sociology and Psychology, Central University of Finance and Economics, 100081, Beijing, China. Email: xinziqiang@sohu.com 
and trust, a recent study showed that activating trustors' high social identity complexity produced a high level of interpersonal trust (Xin, Xin, \& Lin, 2016).

Although the social identity complexity theory has provided a new method to measure the structure of multiple social identities and has been extensively applied to empirical studies, it has some limitations. First, Brewer and colleagues (Brewer, Gonsalkorale, \& van Dommelen, 2013; Brewer \& Pierce, 2005; Miller et al., 2009; Roccas \& Brewer, 2002) were initially concerned with how individuals perceive their own social identities, yet neglected how they represent others' social identities. Decision making in a social interaction process is not only determined by how people represent their own social identities, but also subject to how they represent counterparts' social identities. Second, social identity complexity should be further divided into subjective and objective identities. Brewer et al. presumed that individuals have multiple social identities but differ in the extent to which these identities are perceived as overlapping and interrelated, and regarded the perceived overlap as an index of social identity complexity. In fact, Brewer et al. defined and measured merely the subjective social identity complexity. However, the objective social identities of each individual may be distinct in quantity. Some people have more social identities than others. Comparing with the subjective representation of social identities, the number of actual social identities that individuals possess reflects social identity complexity more directly and objectively, which means the quantity of actual social identities can be an index of objective social identity complexity. To summarise, the social identity complexity theory proposed by Brewer et al. has made a great contribution, yet we should further divide social identity complexity into four types on the two dimensions of subjective-objective and self-others (Xin \& Xin, 2014).

To our knowledge, most previous studies have been concerned with individuals' representation of their own multiple social identities, that is, the subjective social identity complexity of self; however, few studies have examined the other three types of social identity complexity and their relationships with various variables, except one study by Xin and Xin (2014), which found that trustees' objective social identity complexity had a positive effect on their trustworthiness, as perceived by participants. This study provided a new approach to define and measure the objective social identity complexity of trustees (or counterparts). Nevertheless, in this study, social identity complexity was merely divided into low and high complexity (single social identity vs. multiple social identities) so that we could not see how the trustworthiness continuously varied with an increasing number of social identities. Therefore, in the present study, we explored the trend of trustworthiness changing with increased number of the trustees' social identities from one to four, aiming to elaborate the relationship of the two variables.

\section{The Particularity of Social Identity}

Although social identity was originally defined as the individual's knowledge about a part of self-concept derived from the social groups and categories he or she belonged to (Tajfel, 1972), it was often operationally simplified into the category of identity, or an indicator of social category and group membership, which was used to identify in-group members in those studies with regard to social identity complexity theory (e.g., Miller et al., 2009; Schmid et al., 2013; Xin et al., 2016). Following this line of operationalising, the concept of social identity in the current research refers to the identity information of social category or the group membership.

For self-categorisation theory (Turner et al., 1987), a subtheory of social identity perspective (Tajfel \& Turner, 1979), it has been pointed out that social categorisation could cause people to construe themselves and others in the group terms, that is, the social identities (Hogg \& Reid, 2006). A number of previous studies have also found that an individual may perceive and evaluate others on the basis of their social identities (e.g., Brewer, 1988; Brown \& Turner, 1979; Hewstone, Islam, \& Judd, 1993; Kunda, Miller, \& Claire, 1990; Macrae, Bodenhausen, \& Milne, 1995). Trustworthiness is one kind of social perception that can be influenced by the social identity.

Specific to trust research, trustees are often classified as in-group or out-group members based on their social identities. It has been repeatedly proved that trustees who are out-group members are perceived as less trustworthy than trustees who are in-group members (e.g., Brewer, 2008; Platow, Foddy, Yamagishi, Lim, \& Chow, 2012; Tanis \& Postmes, 2005). However, making multiple social identities salient can reduce the importance of any one social identity in classifying in-groups and out-groups and decrease the social distance individuals perceive between themselves and trustees (Xin \& Xin, 2014). Further, individuals may find more similarities between themselves and the trustees with multiple social identities, which subsequently increases the possibility of the two parties belonging to the same group and leads to the trustees being judged as more trustworthy (Xin \& Xin, 2014). These two aspects interpret the potential mechanism of why trustees' objective social identity complexity influences their trustworthiness.

If so, obviously, the other type of personal information (e.g., physical information such as stature, build, and wear) should not have the same function as social identity information, because we seldom use personal physical information to define and recognise a social group or category. Yet the more information about trustees that an individual has obtained can enhance their sense of control (Baronas \& Louis, 1988), which is positively correlated with trust (Rortveit et al., 2015). Therefore, we predicted that increasing the amount of trustees' personal physical information may improve their trustworthiness; however, the impact is not as robust as that of social 
identity, because of the lack of the particular functional mechanism of social identity.

\section{The Current Study}

We conducted two experiments to investigate the effect of trustees' objective social identity complexity on their trustworthiness. Experiment 1 compared the judgments of trustworthiness toward four trustees who had different numbers of social identities, aiming to explore the trend of trustworthiness varying with trustees' objective social identity complexity. Experiment 2 aimed to verify the special effect of social identity information on improving trustworthiness, by paralleling the trustworthiness judgments based on social identity information with the counterpart based on personal physical information irrelevant to social identity.

\section{EXPERIMENT 1 \\ Method \\ Participants}

Fifty-nine students ( 35 female; mean age $=20.25$ years, $S D=1.12$ ) from a university in Beijing individually participated in the 10-minute experiment with a return of $5 \mathrm{RMB}$ as compensation. Their majors included finance, Japanese, law, sociology and mathematics (a total of 33 majors). The desired sample size was estimated using G*Power (Faul, Erdfelder, Buchner, \& Lang, 2009), which confirmed that at least 36 subjects were required to detect a statistically difference with an effect size of $d=.25$, alpha $=.05$ and power $=.95$ when the type of test was a within-subjects analysis of variance (ANOVA).

\section{Design and Procedure}

Experiment 1 was a within-subjects design. The independent variable was the number of a trustee's social identities, which has four levels $(1,2,3$, and 4$)$, and the dependent variable was the trustworthiness of the trustees.

The whole experiment was presented on a computer using custom software written with E-prime 2.0. Participants sat at a distance approximately $50 \mathrm{~cm}$ from the screen. Responses were made using the keyboard. The social identity information of the four trustees was presented in a random order. The four trustees had different numbers ( 1 or 2 or 3 or 4 ) of social identities. Each participant would respectively judge the degree to which the four trustees were trustworthy based on the trustees' social identity information. Their judgments were automatically recorded by the software.

The experiment started with one practice trial in order to familiarise participants with the task and operation of the software. In the practice trial, participants first read the following material to learn about the background of the task: 'Two cars collided at an intersection. Before the traffic police arrived, the two cars had been moved to the roadside. So the police could only depend on the witness's testimony to judge which car should be responsible for this accident. One passenger witnessed this accident. If you were the police, please rate the witness's trustworthiness based on the following information of the witness.' When participants had understood the above descriptions, they could press the space key to watch the next screen. The social identity of the witness was presented on the top of the next screen, and a 7-point scale was presented on the bottom of the screen. Participants were asked to rate the trustworthiness of the witness on the 7-point scale ranging from 1 (least credible) to 7 (most credible) by pressing the corresponding number key at the top of the keyboard. After pressing the number, the practice trial was ended.

In the experiment's trials, the background of the task was a little different. The background was as follows: '... [same as the practice trial]. Four passengers witnessed this accident. Two of the witnesses claimed that the driver of the car driving from south to north should be responsible for this accident, but another two witnesses claimed that the driver of the car driving from north to south should be responsible for this accident. If you were the police, please rate trustworthiness of the four witnesses respectively based on the following information of the witnesses.' As with the practice trial, after participants understood the background of the task, the social identities of the witnesses were presented and participants were asked to rate their trustworthiness. One of the four witnesses had four presented social identities as follows: 'local citizen' (Ben Shi Shi Min), 'enterprise employee' (Qi Ye Yuan Gong), 'university graduate' (Ben Ke Xue Li) and 'Communist Party member' (Gong Chan Dang Yuan). The four identities were common and had the same word length in Chinese (four-character phrases, their Chinese phonetic script were given in parentheses). Another three witnesses had one to three social identities that were randomly selected from the above four identities in each trial. Each witness's information and a 7-point scale were presented on a separate screen, and the four screens for each witness were presented randomly for each participant. Upon the number key press, the current screen was replaced with the next screen. When participants had completed the rating of four witnesses' trustworthiness, they were carefully debriefed and dismissed.

\section{Results and Discussion}

To clarify whether the credibility allotted to each social identity was not different, we examined the judgments of trustworthiness toward the trustees who had one social identity. A between-subjects ANOVA on the judgments of trustworthiness showed that there were no significant differences between the four social identities, $F(3,55)=0.36$, $p>.25, \eta_{p}{ }^{2}=.019$ (Local citizen: $M=4.27, S D=1.67$, $95 \% \mathrm{CI}=[3.60,4.93], N=15$; Enterprise employee: $M=4.33, S D=1.35,95 \% \mathrm{CI}=[3.67,5.00], N=15$; Communist Party member: $M=4.33, S D=1.11,95 \%$ $\mathrm{CI}=[3.67,5.00], N=15$; University graduate: $M=4.71$, $S D=0.83,95 \% \mathrm{CI}=[4.03,5.40], N=14)$. 


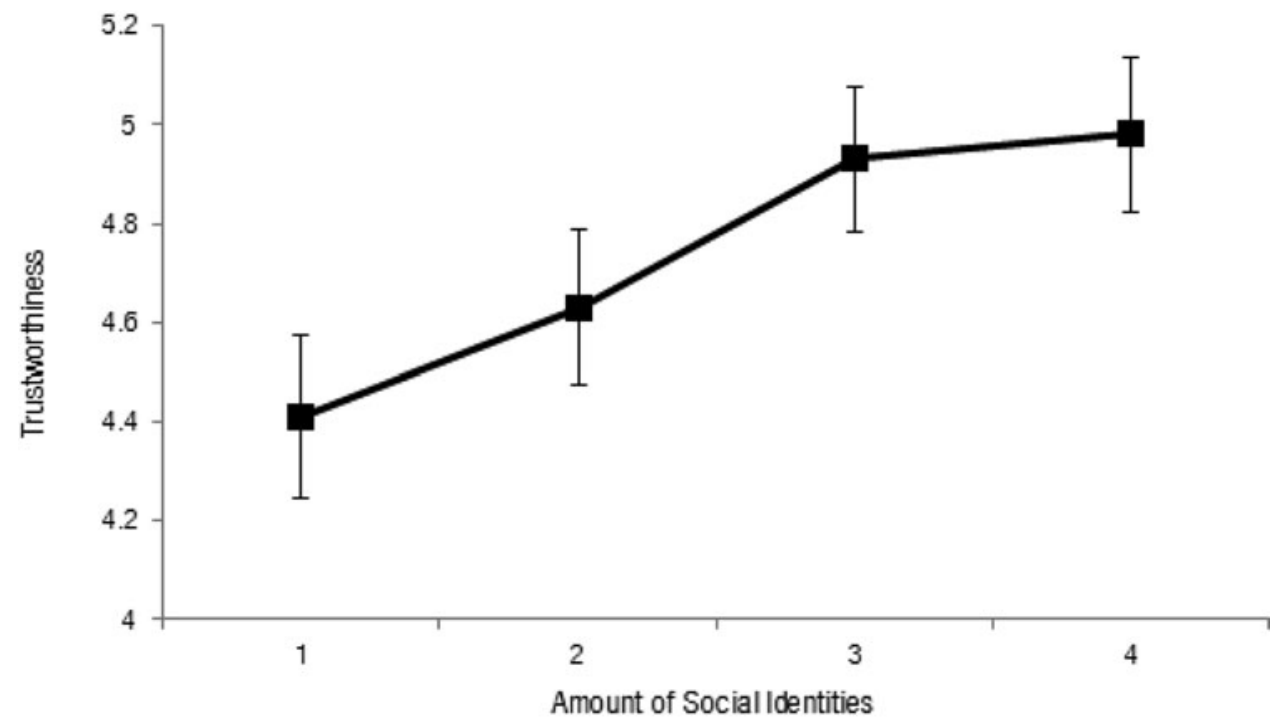

\section{Figure 1}

Mean trustworthiness toward trustees in Experiment 1 as a function of the quantity of social identities that the trustees had. Error bars depict \pm 1 SEM.

As shown in Figure 1, the judgments of trustworthiness rose with the quantity of social identities increasing from 1 to 4 . A within-subjects ANOVA on the judgments of trustworthiness revealed a significant main effect of the quantity of social identities, $F(3,174)=8.64, p<.001$, $\eta_{p}{ }^{2}=.130$. Post hoc tests (LSD) indicated that the judgments of trustworthiness toward both the trustees who had three social identities $(M=4.93, S D=1.11,95 \%$ $\mathrm{CI}=[4.64,5.22])$ and the trustees who had four social identities $(M=4.98, S D=1.20,95 \% \mathrm{CI}=[4.67,5.29])$ were significantly higher than the trustees who had one social identity $(M=4.41, S D=1.26,95 \% \mathrm{CI}=[4.08$, $4.74]$; $p$ s <.001) and the trustee who had two identities $\left(M=4.63, S D=1.20,95 \% \mathrm{CI}=[4.31,4.94] ; p_{1}=.017\right.$, $\left.p_{2}=.011\right)$, but there were no significant differences between the trustees with one social identity and two social identities $(p=.091)$, or between three social identities and four social identities $(p>.25)$.

\section{EXPERIMENT 2}

In Experiment 2, we aimed to strengthen our evidence from Experiment 1 and find out whether the higher rating on trustees' trustworthiness was a result of the increase in the number of social identities, or whether it was only due to more information that enhanced the participants' sense of control (Baronas \& Louis, 1988; Rortveit et al., 2015). We compared the trustworthiness judgment based on social identity information with the one based on physical information irrelevant to the social identities.

\section{Method}

\section{Participants}

One hundred students ( 51 female; mean age $=20.33$ years, $S D=1.56)$ from a university in Beijing individually participated in the 10-minute experiment, with a return of
$5 \mathrm{RMB}$ as compensation. Their majors included finance, social work, law, sociology and mathematics (a total of 39 majors). G* Power analysis indicated that at least 36 subjects were required to detect effects with an effect size of $d=.25$, alpha $=.05$, and power $=.95$ when the type of test was a mixed-design ANOVA.

\section{Design and Procedure}

Experiment 2 was a 4 (the amount of trustee's information: 1 vs. 2 vs. 3 vs. 4 ) $\times 2$ (the type of information: social identity vs. physical information) mixed design, with the amount of information as a within-subjects factor and the type of information as a between-subjects factor. Four words about physical information were as follows: 'wearing black-framed glasses' (Hei Kuang Yan Jing), 'average height' (Shen Gao Zhong Deng), 'thin body' (Ti Xing Pian Shou) and 'wearing a white shirt' (Bai Se Shang Yi). The four words were common and had the same length in Chinese (four-character phrases, their Chinese phonetic script was given in parentheses). Participants were randomly assigned to the two conditions. The experimental environment, apparatus, and procedure were identical to Experiment 1 except that in the physical information group, the presented information of the witnesses was physical information instead of social identities.

\section{Results and Discussion}

We examined how the amount of trustees' information and the information type influenced the judgments of trustees' trustworthiness (depicted in Figure 2).

A mixed-design ANOVA on the judgments of trustworthiness revealed a significant main effect of the amount of information, $F(3,294)=10.84, p<.001, \eta_{p}{ }^{2}=.100$; a significant main effect of the type of information, $F(1$, $98)=17.15, p<.001, \eta_{p}^{2}=.149$; and a significant 
Table 1

The Effect of the Amount and Type of Trustees' Information on Their Trustworthiness in Experiment 2

\begin{tabular}{lll}
\hline & & Trustworthiness \\
\cline { 2 - 3 } Amount & Social identity & Physical information \\
\hline 1 & $4.68(1.06), 95 \% \mathrm{Cl}[4.38,4.98]$ & $4.32(1.17), 95 \% \mathrm{Cl}[3.99,4.65]$ \\
2 & $5.18(1.06), 95 \% \mathrm{Cl}[4.88,5.48]$ & $4.26(1.23), 95 \% \mathrm{Cl}[3.91,4.61]$ \\
3 & $5.14(1.03), 95 \% \mathrm{Cl}[4.85,5.43]$ & $4.68(1.20), 95 \% \mathrm{Cl}[4.34,5.02]$ \\
4 & $5.54(1.01), 95 \% \mathrm{Cl}[5.25,5.83]$ & $4.98(1.20), 95 \% \mathrm{Cl}[4.67,5.29]$ \\
Simple effects & $4>1,2,3 ; 2,3>1 ; 2=3$ & $4>1,2,3 ; 1=2=3$
\end{tabular}

Note: Means, standard deviations (in parentheses), and $95 \%$ confidence intervals (CIs) were calculated with participant as the unit of observation. Trustworthiness was the dependent variable. The amount of trustees' personal information (the 'amount', a within-subjects variable) and the type of information (social identity vs. physical information, a between-subjects variable) were independent variables. The last column lists the simple effects of information type at each level of amount, and the last row lists the simple effects of amount at each level of information type. SI refers to the social identity group and PI refers to physical information group. ' $>$ ' means significantly higher, and '=' means no significant difference (see the text for details). $N=50$ for each group.

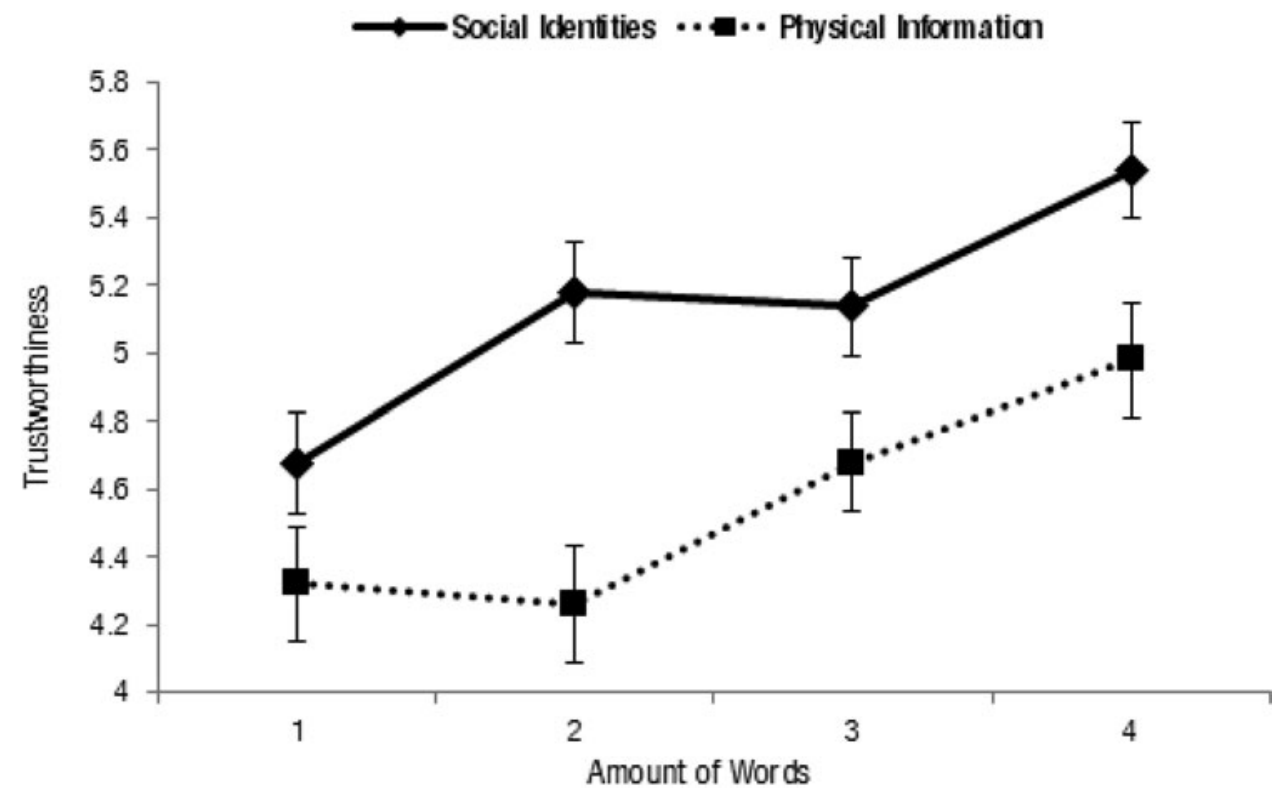

\section{Figure 2}

Mean trustworthiness toward trustees in Experiment 2 as a function of their quantity of social identities or psychical information. Error bars depict \pm 1 SEM.

interaction effect, $F(3,294)=2.72, p=.045, \eta_{p}^{2}=.027$. Table 1 lists the main results from the experiment.

We conducted a within-subjects ANOVA for simple effects of information type at each level of amount. It was found that the judgments of trustworthiness toward the trustees with social identity information were significantly higher than the trustees with physical information when the numbers were two $\left[F(1,98)=16.08, \eta_{p}{ }^{2}=.141\right]$, three $\left[F(1,98)=14.12, \eta_{p}{ }^{2}=.101\right]$, and four $[F(1,98)=14.94$, $\left.\eta_{p}{ }^{2}=.132\right]$, $p s<.001$. But there was no significant difference of trustworthiness between the trustees with different types of information when the number was one $[F(1$, $\left.98)=2.61, p=.11, \eta_{p}^{2}=.026\right]$. These results roughly showed that trustees with social identity information were judged as more trustworthy than those with physical information.

We then analysed simple effects of amount at each level of information type. In the social identity group, there was a significant effect of quantity, $F(3,294)=10.56, p<.001$, $\eta_{p}{ }^{2}=.108$. Following pairwise comparisons indicated that the trustees with four social identities were significantly higher in trustworthiness than those with one social identity $(p<.001)$, and those with two or three identities $(p s=.001)$; the trustees with two or three social identities were significantly higher in trustworthiness than those with one social identity $\left(p_{1}=.001, p_{2}=.003\right)$, but there was no significant difference between those with two and three social identities $(p>.25)$. Altogether, the result pattern was roughly consistent with Experiment 1. For the physical information group, there was also a significant effect of amount, $F(3,294)=3.00, p=.031, \eta_{p}{ }^{2}=.030$; however, the results of pairwise comparisons were different: trustworthiness toward the trustees with four words (phrases) of physical information was significantly higher than that toward the trustees with two or three words $\left(p_{1}=.012, p_{2}=.025\right)$, and marginally significantly higher than that of those with one word of physical information $(p=.071)$, but there were no significant differences between trustworthiness toward the trustees with one, two and three words about physical information ( $p s>.25)$. 
For the two types of information, the trustworthiness increased with the amount of words, but the increase was more pronounced in the social identity group than in the physical information group $\left(\eta_{p}^{2}\right.$ was .108 vs. .030$)$. To substantiate this claim, regression slopes were computed for each participant and compared across the type of information, showing a marginally significant difference between the mean slope of the social identity group $(B=.25)$ and the mean slope of the physical information group $(B=.12), t(98)=1.76, p=.082, d=.35$.

\section{General Discussion}

Based on our conceptual expansion of social identity complexity theory (Brewer \& Pierce, 2005; Roccas \& Brewer, 2002), the present study examined how the objective social identity complexity of trustees affected their trustworthiness. As a whole, Experiments 1 and 2 revealed that with the increase of trustees' objective social identity complexity (i.e., more social identities being presented), their trustworthiness systematically rose. The result supported our hypothesis and was consistent with the previous study (Xin \& Xin, 2014). Experiment 2 found that increasing trustees' other personal information such as physical information did not have such robust effect on trustworthiness as social identity did, which suggests the special and vital role of objective social identity complexity in facilitating trustworthiness.

These results can be interpreted by the particular functional mechanism of social identity. First, individuals might find more similarities between themselves and trustees with high objective social identity complexity, which brings these trustees more possibilities of being classified as in-group members (Crisp \& Hewstone, 2007), even if they were strangers or out-group members. As was found, in-group members are usually perceived as more trustworthy than out-group members (e.g., Brewer, 2008; Platow et al., 2012; Tanis \& Postmes, 2005). Second, trustees' high objective social identity complexity effectively reduces social distance that individuals perceive between themselves and trustees, and closer social distance leads individuals to judge the trustees as more trustworthy (Xin \& Xin, 2014). Previous studies have indicated that the more clues concerning the social characteristics of others we have, the closer the social distance we perceive between ourselves and others (e.g., Charness \& Gneezy, 2008; Hoffman, McCabe, \& Smith, 1996). Social identity could be regarded as a type of social clue. And close social distance can further enhance the judgment of others' trustworthiness (Buchan, Johnson, \& Croson, 2002; Glaeser, Laibson, Scheinkman, \& Soutter, 2000; Rigdon, Ishii, Watabe, \& Kitayama, 2009).

Comparing with social identity information, other types of personal information (e.g., personal physical information in the present research) are not important to classify others as in-group members, nor do they have the same functions mentioned above, such as for reducing so- cial distance. Although increasing the amount of trustees' other personal physical information improves their trustworthiness for enhancing sense of control (Baronas \& Louis, 1988; Rortveit et al., 2015), the effect is not as salient as that of social identity and its effect size is much smaller than increasing the number of social identities.

The present research has important implications. First, we developed a new method to operationalise social identity complexity and proved its special role. Brewer et al. (Brewer \& Pierce, 2005; Miller et al., 2009; Roccas \& Brewer, 2002) measured social identity complexity through the perceived overlap among one's multiple in-group memberships, while the present research used a new index, the quantity of social identities, which could reflect social identity complexity more objectively and directly. Moreover, the present research indeed revealed the special and vital role of objective social identity complexity in facilitating trustworthiness. Based on the two dimensions of subjective-objective and self-others, we provided a new classification of four types of social identity complexity (Xin \& Xin, 2014), which opens a new research field for empirically investigating each type of social identity complexity and its antecedents and consequences.

Second, the present research also has important practical implications with respect to rebuilding social trust. Trust enables people to cooperate with each other (Righetti \& Finkenauer, 2011), contributes to smooth social functioning (Arrow, 1972), and enhances economic efficiency (Fukuyama, 1995). Thus, it is important to maintain a high trust level among individuals or groups. However, the decline of trust has become a prominent social problem in many countries such as United States (Twenge, Campbell, \& Carter, 2014) and China (Xin \& Zhou, 2012; Xin \& Xin, 2017). For example, from 1998 to 2009, interpersonal trust of Chinese college students has decreased by 1.19 standard deviations (Xin \& Zhou, 2012), which suggests that other people and society are increasingly perceived as untrustworthy. The present research provides an easily operational way to improve social identity complexity and subsequently increase trust with its findings that individuals perceived strangers as more trustworthy after becoming aware that trustees possessed multiple social identities.

For instance, a doctor might have other social identities such as driver or party member. The doctor could present his or her multiple identities to the patients via the hospital websites or display boards, to improve his or her trustworthiness. In fact, trust decline and rebuild is a worldwide issue (Xin \& Liu, 2013), so we believe the present findings have extensive implications.

Notwithstanding its contributions, the current research exhibits some limitations. The present two experiments were both carried out with university students, which is a fairly homogeneous sample. The generalisability of the findings to other social groups should be examined and verified in future research. In addition, we did not explore the impact of trustors' social identity complexity 
on their judgment of others' trustworthiness. A previous study has found that activating trustors' high social identity complexity produced a high level of interpersonal trust (Xin et al., 2016). However, the interaction of trustors and trustees' social identity complexity is still unclear. Further research could address this interesting and valuable issue.

\section{Acknowledgments}

The present study was supported by the Major Project of the National Social Science Fund of China (No. 17ZDA325) and the China MOE Project (14JJD190006) of Key Research Institute of Humanities and Social Sciences at Universities (Institute of Developmental Psychology, Beijing Normal University; Ziqiang Xin is an adjunct professor of the institute).

\section{Declaration of Conflicting Interests}

The authors declare that there are no potential conflicts of interest with respect to the research, authorship, and/or publication of this article.

\section{References}

Arrow, K.J. (1972). Gifts and exchanges. Philosophy \& Public Affairs, 1, 343-362. doi:10.2307/2265097

Ashforth, B.E., Harrison, S.H., \& Corley, K.G. (2008). Identification in organizations: An examination of four fundamental questions. Journal of Management, 34, 325-374. doi:10.1177/0149206308316059

Baronas, A.M.K., \& Louis, M.R. (1988). Restoring a sense of control during implementation: How user involvement leads to system acceptance. Mis Quarterly, 12, 111-124. doi: $10.2307 / 248811$

Blader, S. (2007). Let's not forget the 'me' in 'team': Investigating the interface of individual and collective identities. In C. Bartel, S. Blader, \& A. Wrezniewski (Eds.), Identity and the modern organization (pp. 61-84). Mahwah, NJ: Lawrence Erhlbaum Associates.

Brewer, M.B. (1988). A dual process model of impression formation. In R. Wyer \& T. Srull (Eds.), Advances in social cognition (vol. 1, pp. 1-36). Hillsdale, NJ: Lawrence Erlbaum Associates.

Brewer, M.B. (2008). Depersonalized trust and ingroup cooperation. In J.I. Krueger (Ed.), Rationality and social responsibility: Essays in honor of Robyn Mason Dawes (pp. 215-232). New York, NY: Psychology Press.

Brewer, M.B., \& Brown, R.J. (1998). Intergroup relations. In D. Gilbert, S.T. Fiske, \& G. Lindzey (Eds.), Handbook of social psychology (4th ed., pp. 554-594). Boston, MA: McGraw Hill.

Brewer, M.B., Gonsalkorale, K., \& van Dommelen, A. (2013). Social identity complexity: Comparing majority and minority ethnic group members in a multicultural society. Group Processes \& Intergroup Relations, 16, 529-544. doi: $10.1177 / 1368430212468622$

Brewer, M.B., \& Pierce, K.P. (2005). Social identity complexity and outgroup tolerance. Personality and Social Psychology Bulletin, 31, 428-437. doi:10.1177/0146167204271710
Brown, R., \& Turner, J.C. (1979). The criss-cross categorization effect in intergroup discrimination. British Journal of Social Psychology, 18, 371-383. doi:10.1111/ j.2044-8260.1979.tb00907.x

Buchan, N., Johnson, E., \& Croson, R. (2002). Trust and reciprocity: An international experiment. Unpublished manuscript, Wharton School, University of Pennsylvania.

Charness, G., \& Gneezy, U. (2008). What's in a name? Anonymity and social distance in dictator and ultimatum games. Journal of Economic Behavior \& Organization, 68, 29-35. doi:10.2139/ssrn.292857

Chiu, C., \& Cheng, S.Y. (2007). Toward a social psychology of culture and globalization: Some social cognitive consequences of activating two cultures simultaneously. Social and Personality Psychology Compass, 1, 84-100. doi:10.1111/j.1751-9004.2007.00017.x

Crisp, R.J., \& Hewstone, M. (2007). Multiple social categorization. Advances in Experimental Social Psychology, 39, 163254. doi:10.1016/S0065-2601(06)39004-1

Crisp, R.J., Turner, R.N., \& Hewstone, M. (2010). Common ingroups and complex identities: Routes to reducing bias in multiple category contexts. Group Dynamics: Theory, Research, and Practice, 14, 32-46. doi:10.1037/a0017303

Faul, F., Erdfelder, E., Buchner, A., \& Lang, A.G. (2009). Statistical power analyses using $\mathrm{G}^{*}$ Power 3.1: Tests for correlation and regression analyses. Behavior Research Methods, 41, 11491160. doi:10.3758/BRM.41.4.1149

Fukuyama, F. (1995). Trust: The social virtues and the creation of prosperity. New York, NY: Free Press.

Glaeser, E.L., Laibson, D.I., Scheinkman, J.A., \& Soutter, C.L. (2000). Measuring trust. The Quarterly Journal of Economics, $115,811-846$.

Güth, W., Levati, M.V., \& Ploner, M. (2008). Social identity and trust: An experimental investigation. The Journal of SocioEconomics, 37, 1293-1308. doi:10.1016/j.socec.2006.12.080

Hewstone, M., Islam, M.R., \& Judd, C.M. (1993). Models of crossed categorization and intergroup relations. Journal of Personality and Social Psychology, 64, 779-793. doi:10.1037/0022-3514.64.5.779

Hoffman, E., McCabe, K., \& Smith, V.L. (1996). Social distance and other-regarding behavior in dictator games. The American Economic Review, 86, 653-660. doi:10.1257/aer.89.1.340

Hogg, M.A., \& Reid, S.A. (2006). Social identity, selfcategorization, and the communication of group norms. Communication Theory, 16, 7-30. doi:10.1111/ j.1468-2885.2006.00003.x

Kramer, R.M. (1999). Trust and distrust in organizations: Emerging perspectives, enduring questions. Annual Review of Psychology, 50, 569-598. doi:10.1146/annurev.psych.50.1.569

Kunda, Z., Miller, D.T., \& Claire, T. (1990). Combining social concepts: The role of causal reasoning. Cognitive Science, 14, 551-577. doi:10.1207/s15516709cog1404_3

Lount, R.B. (2010). The impact of positive mood on trust in interpersonal and intergroup interactions. Journal of Personality and Social Psychology, 98, 420-433. doi:10.1037/a0017344 
Macrae, C.N., Bodenhausen, G.V., \& Milne, A.B. (1995). The dissection of selection in person perception: Inhibitory processes in social stereotyping. Journal of Personality and Social Psychology, 69, 397-407. doi:10.1037/0022-3514.69. 3.397

Maddux, W.W., \& Brewer, M.B. (2005). Gender differences in the relational and collective bases for trust. Group Processes \& Intergroup Relations, 8, 159-171. doi:10.1177/ 1368430205051065

Miller, K.P., Brewer, M.B., \& Arbuckle, N.L. (2009). Social identity complexity: Its correlates and antecedents. Group Processes \& Intergroup Relations, 12, 79-94. doi:10.1177/1368430208098778

Platow, M.J., Foddy, M., Yamagishi, T., Lim, L., \& Chow, A. (2012). Two experimental tests of trust in in-group strangers: The moderating role of common knowledge of group membership. European Journal of Social Psychology, 42, 30-35. doi:10.1002/ejsp.852

Rigdon, M., Ishii, K., Watabe, M., \& Kitayama, S. (2009). Minimal social cues in the dictator game. Journal of Economic Psychology, 30, 358-367. doi:10.1016/j.joep.2009.02.002

Righetti, F., \& Finkenauer, C. (2011). If you are able to control yourself, I will trust you: The role of perceived self-control in interpersonal trust. Journal of Personality and Social Psychology, 100, 874-886. doi:10.1037/a0021827

Roccas, S., \& Brewer, M.B. (2002). Social identity complexity. Personality and Social Psychology Review, 6, 88-106. doi:10.1207/S15327957PSPR0602_01

Rortveit, K., Hansen, B., Leiknes, I., Joa, I., Testad, I., \& Severinsson, I.E. (2015). Patients' experiences of trust in the patient-nurse relationship - A systematic review of qualitative studies. Open Journal of Nursing, 5, 195-209. doi:10.4236/ojn.2015.53024

Schmid, K., Hewstone, M., \& Al Ramiah, A. (2013). Neighborhood diversity and social identity complexity implications for intergroup relations. Social Psychological and Personality Science, 4, 135-142. doi:10.1177/1948550612446972

Tajfel, H. (1972). Social categorization. English manuscript of 'La categorisation sociale'. In S. Moscovici (Ed.), Introduc- tion a la psychologie sociale (vol. 1, pp. 272-302). Paris: Larousse.

Tajfel, H., \& Turner, J.C. (1979). An integrative theory of intergroup conflict. In W.G. Austin \& S. Worchel (Eds.), The social psychology of intergroup relations (pp. 33-47). Monterey, CA: Brooks/Cole.

Tanis, M., \& Postmes, T. (2005). A social identity approach to trust: Interpersonal perception, group membership and trusting behaviour. European Journal of Social Psychology, 35, 413-424. doi:10.1002/ejsp.256

Turner, J.C., Hogg, M.A., Oakes, P.J., Reicher, S.D., \& Wetherell, M.S. (1987). Rediscovering the social group: A selfcategorization theory. Oxford, UK: Blackwell.

Twenge, J.M., Campbell, W.K., \& Carter, N.T. (2014). Declines in trust in others and confidence in institutions among American adults and late adolescents, 1972-2012. Psychological Science, 25, 1914-1923. doi:10.1177/0956797614545133

Xin, S.F., Xin, Z.Q., \& Lin, C.D. (2016). Effects of trustors' social identity complexity on interpersonal and intergroup trust. European Journal of Social Psychology, 46, 428-440. doi:10.1002/ejsp.2156

Xin, Z.Q., \& Liu, G.F. (2013). Homo economicus belief inhibits trust. PLoS One, 8, e76671. doi:10.1371/journal.pone.0076671

Xin, Z.Q., \& Xin, S.F. (2014). The influence of trustees' social identity complexity on their trustworthiness. Acta Psychologica Sinica, 46, 415-426. doi:10.3724/SP.J.1041.2014. 00415

Xin, Z.Q., \& Xin, S.F. (2017). Marketization process predicts trust decline in China. Journal of Economic Psychology, 62, 120-129. doi:10.1016/j.joep.2017.07.001

Xin, Z.Q., \& Zhou, Z. (2012). A cross-temporal metaanalysis of changes in Chinese college students' interpersonal trust. Advances in Psychological Science, 20, 344-353. doi:10.3724/SP.J.1042.2012.00344

Yuki, M., Maddux, W.W., Brewer, M.B., \& Takemura, K. (2005). Cross-cultural differences in relationship-and group-based trust. Personality and Social Psychology Bulletin, 31, 48-62. doi:10.1177/0146167204271305 